\title{
Electrocardiogram QT Corrected Interval Prolonged, CTCAE
}

National Cancer Institute

\section{Source}

National Cancer Institute. Electrocardiogram QT Corrected Interval Prolonged, CT CAE. NCl Thesaurus. Code C143437.

A finding of a cardiac dysrhythmia characterized by an abnormally long corrected QT interval. 